\title{
Dá-me tua rebeldia que eu te compro uns belos sapatos: 0 "ser admirável" como moeda midiática de troca*
}

RESUMO

Tomando como objeto de análise a telenovela mexicana Rebelde, tem-se por objetivo problematizar algumas das bases estésicas e estéticas que compõem o modo de aparecimento juvenil neste produto midiático, problematizando, entre outros, o sistema de agenciamento do gosto ali evidenciado e as estratégias de visibilidade por ele articuladas. Dialogando com Landowsky, Morin e Prokop, entre outros, propõe uma reflexão sobre alguns dos impactos das articulações entre imagem do jovem e imaginário juvenil propostas e percebidas desde esta telenovela.

\section{PALAVRAS-CHAVE}

mídia

visibilidade

juventude

\section{ABSTRACT}

Taking Mexican soap opera Rebelde as an object of analysis, the article intends to question some of the aesthetic bases that articulate the visibility of youth in this media product, arguing, among other factors, the system of taste's agency that is highlighted and the strategies of visibility articulated on it. Mobilizing authors like Landowsky, Morin and Prokop, proposes a reflection on some impacts of the links established between images and imagination of young people proposed and perceived from this soap opera.

\section{KEY WORDS}

media

visibility

youth

\section{Rose de Melo Rocha}

Coordenadora adjunta do Mestrado em Comunicacãa e Práticas de Consumo da ESPM/SP/BR

rrocha@espm.br
Há alguns anos, um verdadeiro fenômeno midiático tomou de assalto as mentes e corpos de setores juvenis brasileiros. Ancorada na apropriação de gêneros televisivos de forte fundamento melodramático, a telenovela mexicana Rebelde trazia a nosso cotidiano uma mescla curiosa e estigmatizada de cultura de elite, "alma latina" e padrões consumistas referentes ao que de mais estereotipado existe nos modelos neoliberais. Todavia, o consumo - simbólico e material - do fenômeno Rebelde não conheceu, em território nacional, clássicas fronteiras de classe. Fenômeno de massa, potencializado pela existência de uma banda juvenil de mesmo nome, composta por atores/personagens da telenovela, encantava com proporcional significação a jovens pertencentes aos mais díspares estratos sociais ${ }^{1}$.

Problematizando algumas das bases estésicas e estéticas que compõem o modo de aparecimento juvenil capitaneado por este produto massivo, analisamos neste artigo algumas das engrenagens possíveis a operarem em suas estratégias de produção de sentido, que incluem, de modo superlativo, processos e circulação de bens materiais e simbólicos concernentes a uma ampla rede midiática. Ganha destaque a pluricentralidade do sistema de agenciamento do gosto ali evidenciado e as estratégias de visibilidade do jovem por ele articuladas - respondendo a padrões que advogam elementos supostamente universais de um "ser jovem" - e supostamente rebelde - que em verdade são bastante idiossincráticos.

\section{Declarar o gosto é afirmação de si e estratégia de visibilidade, tomando parte de nossos rituais de encontro societal, de reconhecimento e demarcação de diferença.}

Para dar sustentação ao argumento que se pretende desenvolver, tomaremos como ponto de partida a leitura de alguns textos que nos parecem fundamentais. Assumindo inicialmente por referencial dialógico a interpretação proposta por Eric Landowsky (1997), traremos ao debate a noção mesma do "gosto", concordando incisivamente com o que nos propõe este autor: gosto, sim, se discute.

Avaliando as dinâmicas e efeitos de sentido evocados 
pela produção e incorporação cotidiana de determinadas estratégias associadas ao gosto - o gosto da gente, o gosto das coisas, o gosto dos outros - o sócio-semioticista francês esclarece que, em um primeiro momento, o gosto é articulado à subjetividade. Assim, declarar o gosto é afirmação de si e estratégia de visibilidade, tomando parte de nossos rituais de encontro societal, de reconhecimento e demarcação de diferença. Não por acaso, nota Landowsky, convivemos frequentemente com maníacos por declarar o gosto:

[...] existem indivíduos que, acreditando que todos aqueles que os escutam devem ter interesse e simpatia por sua pessoa, transformam numa verdadeira mania seu costume de expor extensamente aos demais, quase em qualquer ocasião, os próprios gostos. (Landowsky, 1997, p.99).

Desse modo, importa nesta definição não apenas do que se gosta, mas, também, como se gosta do que se gosta. Para citar um exemplo, podemos lembrar da admiração pelo bizarro e pelo tosco, tão recorrente em narrativas juvenis sobre a cultura midiática. Ela passa, de certo modo, por uma "autorização", auto-imputada ou de fundamento inter-grupal, para se gostar, inclusive, de coisas que podem ser consideradas por outros como sendo de absoluto mau gosto.

Prosseguindo nas associações sugeridas por Landowsky, encontramos que os gostos são inicialmente associados ao sujeito. Este teria um "gosto" pessoal e singular; um sistema próprio de "atrações e repulsões". Tal proposição nos serve aqui tanto para pensar a articulação interna da telenovela Rebelde, quanto para problematizarmos a passagem fundamental a ser considerada no nosso artigo, ou seja, o rompimento de fronteiras, as pontes que, partindo do consumo imediato e circunstancial do produto midiático, se estabelecem para além dele.

\section{São as paixões molares $\mathrm{e}$}

menos os amores moleculares

que organizam, para além da

narrativa, as disputas externas e

também extremadas entre fãs e anti-fás de Rebelde.

Nos referimos às partilhas sociais e às práticas de consumo que, em âmbitos do dia-a-dia, reiteram os valores e estilos de vida ali propostos, compreendendo, obviamente, tanto as atualizações que se pretendem ipsis litteris, quanto aquelas que muito claramente se assumem como uma ressignificação. Jovens consumidores de Rebelde fazem desde dinâmicas materiais e simbólicas múltiplas. Os diferentes fluxos de consumo identificados na lógica de produção e na estruturação narrativa de Rebelde convidam ou, antes, permitem esta ramificação das apropriações.

Adotando a terminologia de Arjun Appadurai (1990), podemos perceber a convivência de alguns fluxos da chamada cultura global centrais a este processo. Se nos voltarmos a uma análise da estrutura formal e dos elementos de conteúdo da narrativa encontramos semelhanças com o ideopanaronama e o midiapanorama propostos por Appadurai. Refletindo, em outra perspectiva, sobre os dados contextuais e sócioculturais de sua produção e consumo, encontramos uma economia política da mídia sustentada por etnopanoramas, tecnopanormas e finançopanoramas significativos.

De um lado, panoramas e fluxos culturais, de outro, uma cena local de reapropriação, peculiar e particular aos consumidores desde suas temporalidades e espacialidades mais imediatas. Analisando especificamente a apropriação, pelo espectador, da narrativa midiática, de seus efeitos de sentido e de seus indicadores de consumo material, notamos a complexa e por vezes fragmentada rede de apropriações que daí pode emergir. Assim, a reiterada operação narrativa com estereótipos e estigmatizações não é incoerente à articulação em larga dose de certa moralidade circunstancial. Em sentido similar, a pluralidade interpretativa não exclui iniciativas de apropriação mais fundamentalistas.

Autor representativo na conceituação das sociedades de controle, Deleuze (1992) vê que estas sucedem as sociedades disciplinares, exercendo um controle "de curto prazo e de rotação rápida, mas também contínuo e ilimitado". Controlar, hoje, significa "cifrar", criar senhas de acesso à informação ou à rejeição:

Não se está mais diante do par massa-indivíduo. Os indivíduos tornaram-se "dividuais", divisíveis, e as massas tornaram-se amostras, dados, mercados ou "bancos" (Deleuze, 1992, p.222).

Uma das respostas a este problema pode ser encontrada se nos detivermos na argumentação formulada por Deleuze e Guattari a propósito da segmentaridade. Este estudo revela que somos segmentarizados binariamente, circularmente e linearmente, sendo que tais figuras "passam umas nas outras, transformando-se de acordo com o ponto de vista". "A vida moderna", dizem eles, "não destituiu a segmentaridade". Mas, em suma, "a endureceu singularmente" (Deleuze \& Guattari, 1996, p.84).

Para perceber a dimensão deste endurecimento, 
consideremos o que os autores nos dizem acerca da mutação da segmentaridade circular, comparando-se as sociedades ditas primitivas e as modernas:

A segmentaridade torna-se dura, na medida em que todos os centros ressoam, todos os buracos negros caem num ponto de acumulação - como num ponto de cruzamento em algum lugar atrás de todos os olhos. O rosto do pai, do professor primário, do coronel, do patrão se põem a redundar, remetendo a um centro de significância que percorre os diversos círculos e repassa todos os segmentos. As microcabeças flexíveis, as rostificações animais são substituídas por um macro-rosto cujo centro está por toda parte e a circunferência em parte alguma. Não se tem mais n olhos no céu ou nos devires vegetais e animais, mas sim um olho central computador que varre todos os raios (Deleuze \& Guattari, 1996, p.87).

A organização da ressonância à qual se referem, e da qual o Estado seria o principal aparelho, leva-me à seguinte proposição. Nas sociedades midiáticas ou, para usar a terminologia de Perniola (1993), nas mediacracias, cabe aos meios de comunicação, já sintonizados com a cultura tecnológica, a função de "caixas de reverberação" das imagens-acontecimentos, das imagens-pessoas, das imagens-sensações, das imagens-estilos-de-vida e assim por diante.

Ao se defrontarem com esta segmentaridade molar, endurecida, com as máquinas abstratas de sobrecodificação, Deleuze e Guattari notam, entretanto, que, em uma de suas manifestações,

quanto mais a organização molar é forte, mais ela própria suscita uma molecularização de seus elementos, suas relações e seus aparelhos elementares. Quando a máquina torna-se planetária ou cósmica, os agenciamentos têm uma tendência cada vez maior a se miniaturizar e a tornar-se microagenciamentos (Deleuze \& Guattari, 1996, p.93).

Recorrendo à reflexão de Deleuze e Guattari sobre a circulação molar/molecular notamos que, em verdade, esta oscilação é uma constante no discurso midiático engendrado por Rebelde. Molar é a escola que aglutina a maior parte das cenas da telenovela: elitista, oferecendo bolsas de estudo apenas para que opere livremente na criação de suas regras de conduta. Molecular é o figurino dos personagens, em especial o uniforme das meninas: gravatas convivem com minissaias e botas pretas de cano alto e salto fino. Molares são as dicotomias forte/ fraco, honesto/cafajeste, amigo/inimigo, rico/pobre, magro/gordo, belo/feio. Molecular é a paisagem sonora costurada pela trilha sonora da telenovela, repleta de música eletrônica e sincopada.

São as paixões molares e menos os amores moleculares que organizam, para além da narrativa, as disputas externas e também extremadas entre fãs e anti-fãs de Rebelde. Gostar/não-gostar da telenovela e de seus personagens responde a padrões antitéticos, a pertencimentos endurecidos, refratários, a adesões incondicionais, aquelas mesmas que, por seu turno, organizam a convivialidade e os enfrentamentos dos grupos juvenis na cena midiática propriamente dita. Flexível em alguns aspectos, endurecido em outros, Rebelde constitui-se menos como uma obra aberta e, mais propriamente, como uma narrativa ambivalente.

Propondo a discussão de sistemas, critérios e fundamentos de estabelecimento de gostos, valores e julgamentos, e advogando a existência de uma objetividade mínima a guiar esta interpretação, é novamente Landowsky (1997) quem nos propõe a identificação de dois modelos fundamentais que podem combinar-se entre si. O primeiro, é nomeado o "gosto de gozar"; o segundo o "gosto de agradar".

No modelo "gosto de gozar" o encanto não está no novo do objeto, mas nas sensações que ele provoca ou dele decorrem, evidenciando uma base auto-centrada e auto-erótica de satisfação. No "gosto de agradar", o que interessa é que outros gostem... de mim!. Segundo Landowsky, "ao gosto de gozar o mundo sobrepõe-se, assim, à maneira de um segundo princípio regulador das relações que cada um entretém com seu meio ambiente, o gosto complementar de agradar a outrem" (Landowsky, 1997, p.112).

A primeira forma de gosto tem uma forte base objetal, o prazer sendo obtido através das qualidades dos objetos, da atração ou repulsão causada. A segunda forma expressa uma natureza subjetal, por definição estabelecida em relação com outro sujeito. Trata-se, neste caso, de agradar para "ser" (aceito, amado, reconhecido, legitimado).

Os "gostos da gente" revelam as conflituosas dinâmicas articuladas pela convivência, opção ou adesão (voluntária ou assujeitada) a estes dois princípios reguladores. Em alguns casos, é verdadeiramente obsessiva a jornada empreendida para se tornar "o objeto do gosto do outro": é preciso transformar-se em objeto, em resumo.

Trata-se de uma dupla imputação, através da qual se atribuem características objetais a sujeitos e característica subjetivas a objetos. Esta é uma importante base de funcionamento da mídia, de sua percepção e de sua participação nos sistemas sociais e simbólicos de agenciamento dos gostos e dos julgamentos de gosto. Segundo Landowsky, há um eterno conflito entre gozo individual e êxito social, entre a busca da aceitação (social) e da distinção (pessoal).

Tais composições bipolares não são estranhas ao universo juvenil retratado por Rebelde. Este conflito é um vetor estruturante bastante significativo na sua 
linguagem e um midiapanorama paradigmático do seu modo de apresentação. Sobre isso, Appadurai (1999) diz o seguinte:

Os midiapanoramas [...] oferecem aos que os conhecem e transformam [...] uma série de elementos (tais como personagens, enredos e formas textuais), dos quais podem ser formados scripts de vidas imaginárias baseadas no próprio ambiente dos espectadores ou de espectadores que vivem em outros ambientes. Esses scripts podem e realmente ficam desagregados em conjuntos complexos de metáforas por meio das quais as pessoas levam a sua vida (Lakoff \& Johnson, 1980), uma vez que contribuem para narrativas do "outro" e protonarrativas de vidas possíveis, de fantasias que podem transformar em preâmbulos de desejo de aquisição e movimento. (Appadurai, 1999, p.315-316).

Vivemos atualmente a intensificação de um advento existencial bastante curioso, proposto, em uma primeira abordagem, pela psicanalista Anna Verônica Mautner (2002): trata-se da "grifagem", da constituição de "seresgrife". Nas palavras de Mautner, em um mundo no qual o Castelo de Caras é o grande escoadouro e o grande barômetro de certa existência ou notoriedade, é preciso que as figuras públicas tornem-se "grifadas", assim como, podemos sugerir, é preciso que, para garantir seu pertencimento a uma linhagem de marca, os produtos recebam seus indefectíveis códigos de barra. Círculo, circuito de imagens: no mundo dos "seres-grife", quem devora quem? (Rocha, 2004, p.160).

Em verdade, qualquer um, qualquer um que o seja bastante comum, pode, em um passe de imagem, fazer ecoar os fracionamentos, atualizando-os em presença. Devem, para tanto, possuir "estilo", curiosa nomeação que mais parece um atributo decorativo, revelada na demonstração de um saber jogar com os pedaços que compõem sua imagem, como se pode "saber jogar" com diferentes peças de roupa.

\section{A sustentação do fascínio} alimenta-se exatamente da evocação das figuras menores, dos estranhos familiares: para que o show do medium não seja ofuscado, depende-se de figuração mediana ou, tanto melhor, assumidamente medíocre.
Se nos remetermos à argumentação de Michel Kokoreff (1988), encontraremos, nas sociedades midiáticas, um deslocamento substantivo nos processos de atribuição de relevância social. Referindo-se especificamente à tevê, observa que a própria se anuncia como o grande atrativo, na atribuição desmesurada de importância a si mesma. Na leitura de Kokoreff, esta tendência traduz uma transformação global dos modos sociais de representação e de troca, segundo a qual a mídia torna-se seu próprio fim (Kokoreff, 1988:37).

No quadro de autocelebração proposto pelo autor, a mídia mobiliza os signos de sua excelência, exibindo a matriz técnica e jogando astutamente com a fascinação das imagens. Não há inocência na incitação ao diálogo, à interação que ela promove. Neste processo, que o autor compara a um "reaquecimento do social", já não se trata mais de mobilizar a opinião pública, mas, sim, de fazer do social um grande show: "pelo poder mágico da tela, os problemas da sociedade se metamorfoseiam em acontecimentos midiáticos".

Desinvestidos de sua carga negativa, submetidos a um "tratamento emocional de superfície", estes problemas são absorvidos, persuadindo-nos, paradoxalmente, da necessidade e da grandeza do duplo midiático (Kokoreff, 1988, p.39). Neste contexto, não cabem outros atores "maiores". A sustentação do fascínio alimenta-se exatamente da evocação das figuras menores, dos estranhos familiares: para que o show do medium não seja ofuscado, depende-se de figuração mediana ou, tanto melhor, assumidamente medíocre. A autocelebração, acrescenta por sua vez Kokoreff, ilustra-se pela implantação definitiva da televisão no star system, valendo-se de "estrelas" da informação e do divertimento de massa ancoradas na familiaridade e, nestes moldes, na repersonalização dos liames com o público.

As descrições feitas destas "estrelas da tela", caracterizadas, para Kokoreff, pela "cotidianidade de sua presença e superexposição midiática", são muito adequadas à compreensão das celebridades "rebeldes", sedutoras e intensas na igual proporção em que se anunciam efêmeras e voláteis. Um arrebatamento quase místico cerca o consumo destas celebridades juvenis, hedonistas e egocentradas ao extremo e, ao mesmo tempo absolutamente abertas ao consumo, desmembradas que são em múltiplos fragmentos de consumo, fractalizadas - e devoradas aos pedaços: sandálias, toalhas, discos, dvd's, camisetas, figurinhas.

Recurso de fundamento tautológico, a promoção destas múltiplas e pequeninas "estrelas" encontra, na massa de telespectadores, não mais do que um "álibi ficcional", "consagrado por sua fidelidade, seu gosto, seu poder abstrato de apreciação" (Kokoreff, 1988, p.39-41). Em seus estudos sobre o neo-individualismo Gilles Lipovetsky (1989) problematiza, como um de 
seus sintomas mais contundentes, a personalização e psicologização do corpo.

Destacando a existência de um verdadeiro self-sevice libidinal a serviço do culto ao corpo e da juvenilização, defende que esta normalização é um interesse que obedece a imperativos sociais. Segundo afirma, o corpo disponível para todas as experimentações está também disponível ao controle:

o objeto e o sexo entraram, com efeito, no mesmo ciclo ilimitado da manipulação sofisticada, da exibição e da proeza, dos comandos à distância, das interconexões e comutações de circuitos, de "teclas sensitivas", de combinatórias livres de programas, de existência visual absoluta. (Lipovetsky, 1989, p.32).

Como estratégia para complementar a análise deste modo de "ser jovem" e "rebelde" representado na telenovela, utilizaremos como tipos exemplares dois personagens centrais da trama, especialmente porque em torno deles se materializam conflitos bastante centrais à narrativa. De um lado temos Mía Colucci, de outro seu par romântico, Miguel Arango, dupla que atualiza dramas românticos clássicos, com componentes emblemáticos como desejo de vingança, diferença de classe social, traição e sujeição a intrigas.

Mía e Miguel encarnam no início da trama situação que se modifica ao longo das temporadas - a expressão acabada de garotos bons-maus. Mía, de uma ingenuidade pueril, é capaz, no entanto, de agressões verbais que externalizam forte preconceito de classe. Miguel, o sujeito bom, simples e autêntico, na verdade esconde suas motivações mais íntimas. Como somos informados logo de início, Arango entra para o "Elite Way" com o claro objetivo de vingar-se. Seu alvo: a doce e artificiosa Mía, filha do suposto assassino de seu pai.

\section{0 discurso amoroso é um} ordenador central na evolução destes personagens. Na vasta rede de intrigas, traições e fidelizações que estrutura a telenovela, as adesões e ódios são extremados.

Mía é odiada por algumas garotas, pois, como menciona uma delas em um dos episódios, "tudo sempre dá certo com ela". Colucci, por sua vez, toma de fato para si o papel modelar, assumindo às vezes com arrogância o seu suposto "bom gosto" para se vestir. Este ser "admirável" passeia desenvoltamente pelo universo dos artifícios a ponto de sua inegável beleza ser quase eclipsada pelo arsenal embelezador: cabelos alongados, clareados, repletos de mechas, pele excessivamente e artificialmente bronzeada, voz infantil, oscilando dos gritinhos aos choramingos. Uma bonequinha de luxo, erotizada e vulnerável, que tem por convicção só iniciar sua vida sexual - entregar-se, é a expressão utilizada - para um homem que ame e, citando novamente a personagem, em quem "confio integralmente".

Miguel Arango, belo e rude, algo como um "caipirão" na leitura inicial de Mía, também se rende ao amor embora, antes, tenha se entregado ao sexo. Bêbado, em um dos episódios Arango transa com outra garota, isto logo antes de consumar, o que acaba não ocorrendo no momento previsto, sua primeira noite com Mía, sua então namorada. Visões dicotômicas são mantidas, embora ganhando contornos digamos mais atualizados. De um lado, a garota sedutora-maliciosa, que se aproveita da embriaguez do rapaz comprometido para envolvê-lo sexualmente. De outro, a garota sedutoraromântica, que se guarda para um homem especial, de confiança, embora não mais tenha que esperar o casamento para tornar-se sexualmente ativa.

O discurso amoroso é um ordenador central na evolução destes personagens. Na vasta rede de intrigas, traições e fidelizações que estrutura a telenovela, as adesões e ódios são extremados. Amigos são amigos para o que der e vier, inimigos idem. Matizando esta polarização, o amor. Ou, em outras situações, a coesão grupal que também supera esta diferença radical de gostos e gostares. É o que se nota nas ações corporativas dos estudantes contra professores odiados que podem, por exemplo, receber de "presente" uma cobra durante a aula.

Curiosamente, os professores menos arbitrários são os que concentram maior grau de rejeição. Uma delas, exatamente a que recebe a cobra, é representada segundo elementos estereotípicos clássicos. Desprovida de encanto, usando óculos e cabelo desajeitadamente preso em um rabo-de-cavalo, roupas de tom escuro, largas, utiliza de sua autoridade para manter a ordem na classe, algo expresso, inclusive, na rigidez com que aplica e avalia os exames da disciplina.

Esta mulher madura e desprovida de glamour e atrativos físicos opõe-se flagrantemente a outra figura feminina da trama, a mesma Mía Colucci, a quem abertamente critica devido a seus atributos cuidadosamente cultivados. O diretor autoritário e atrapalhado, o professor boa-pinta e boa-gente, estes não são alvo direto de rebeldia. Antes, parecem reforçar os complicados e idiossincráticos códigos de conduta referendados pelos "rebeldes".

Midiaticamente admiráveis, humanamente comu- 
táveis. Os jovens de Rebelde e suas personas performativas corroboram o universo da hiperconectividade teorizado por autores como Bauman (2004, p.7):

Ulrich, o herói do grande romance de Robert Musil era - como anunciava o título da obra - Der Mann ohne Eingenschaften: o homem sem qualidades. Não tendo qualidades próprias, herdadas ou adquiridas e incorporadas, Ulrich teve de produzir por conta própria quaisquer qualidades que desejasse possuir, usando a perspicácia e a sagacidade de que era dotado; mas nenhuma delas tinha garantia de perdurar indefinidamente num mundo repleto de sinais confusos, propenso a mudar com rapidez e de forma imprevisível.

Para Dieter Prokop (1986, p.166), passamos dos heróis às figuras "sintético-artificiais", sendo que "as combinações de signos ocorre conscientemente e todos sabem que se trata de signos de marcas". Voltamos, assim, à construção do gosto. Os "rebeldes", de um lado, parecem exemplares acabados do êxtase do instante, buscando febrilmente cumprir ao princípio auto-suficiente do Gozo. O outro é aqui puramente objetal, interessando apenas naquilo que faz gozar. Aos consumidores, por sua vez, tem-se uma modulação da mesma lógica: ele também busca fundir-se com o objeto midiático, no afã de se tornarem unos, indivisíveis. De outro, o princípio relacional do Agradar.

\section{Quer ser um sujeito, ainda que, para isto, deva permanecer, irrevogavelmente, em fiel e eferna tensão, cultivando a seu invólucro objetal.}

Também para os "rebeldes da ficção" quanto para os "rebeldes da consumação", em uma capciosa simplificação das inseguranças tipicamente adolescentes, o outro é, igualmente, a instância super poderosa à qual se dirigir. Mesmo se for necessário nos tornamos nós próprios objetos para que melhor de nós este outro possa gozar, para que, enfim, nós possamos agradálo. E aqui está a base do conflito. Queremos agradar, mas desejamos que, ainda assim, este "outro" possa nos perceber como sujeitos e não apenas nos desfrutar como objetos.

Segundo Dieter Prokop (1986) os produtos de monopólio operam segundo uma lógica de agenciamento de desejos, em uma lógica pendular de fascinação e tédio. Para este autor, a fascinação se dá tanto pelo meio quanto pela forma, existindo "bons produtos" capazes de fascinar. Estes, para Prokop, apresentam "uma relação não-instrumental com o objeto", e "são, neste sentido, produzidos livremente, eles criam seu público pelo desenvolvimento de uma estrutura autônoma". E, deste modo, o sociólogo chega a uma hipótese de que "todos os resultados empíricos mostram que a maioria das pessoas rejeita estruturas autônomas de produtos e, em vez disso, preferem formas instrumentalizadas de cultura, estruturas de produtos, portanto, que não provocam nenhuma recepção dissonante".

Para Prokop os produtos de monopólio acumulam "valores modais de fantasia", contando, para isto com uma "signalidade encenada profissionalmente". Segundo o autor, estes produtos passam, progressivamente, a contar com uma figura feminina curiosa, diversa da vamp fílmica pré-monopolista da década de 10/20. É a chamada garota "boa-má" que demonstra "que é possível associar sexo a uma troca leal" (Prokop, 1986, p.162-163).

Neste aspecto, Mía, degeneração da garota "boamá" é uma representação do feminino profundamente paradoxal. Ninfeta erotizada/deserotizada habita inicialmente a cena de Rebelde como um significante puro, significando, essencialmente, pela superfície modal e modelar de sua aparência. Posteriormente, temos um corpo feminino que, jogando com a submissão e com seu caráter objetal, astuciosamente constrói a própria afirmação como sujeito. Midiaticamente admirável, artificial e artificiosa, equilibra-se, tal como uma trapezista em uma caixa de música tecno. Ela também quer ser amada. E aqui, mais uma vez, não pelo que parece ser, mas, antes, por suas qualidades interiores. Quer ser um sujeito, ainda que, para isto, deva permanecer, irrevogavelmente, em fiel e eterna tensão, cultivando a seu invólucro objetal.

Retomamos, neste ponto, debates intelectuais mais diretamente articulados a produtos culturais que, desde o nascimento mesmo da indústria cultural, passando, posteriormente, pelo que Edgar Morin (2003) denominou a crise da cultura de massa (com a consequente perda de seu caráter homogeneizante, isto já em meados da década de 60). Mais contemporaneamente, podemos enunciar como a passagem definitiva de uma cultura massiva para uma cultura midiática, na qual o consumo se segmenta, a recepção se pluraliza e a produção pode iniciar exercícios de criação mais afeitos ao caráter maciço da disseminação cultural do que propriamente à pressuposição de uma audiência de massa facilmente tipificada por padrões médios de repertório e de recepção.

Um antigo texto, mas ainda um clássico para as teorias da comunicação, escrito por Umberto Eco (1979), e tantas vezes adotado de modo equivocado ou quase mesmo na contramão da linha interpretativa proposta pelo autor, já nos alertava, corroborando, 
desde pontos de vista outros, a algumas das proposições morinianas, para a necessária compreensão da chamada cultura de massa em acepções descongestionadas que a considerem, inclusive, anticultural em relação à cultura dita ilustrada.

Foi o mesmo Morin que nos permitiu compreender, desde um recorrido histórico, que a terceira etapa da cultura de massas desvelou a convivência de dois movimentos, uma onda de choque - disruptiva - e uma onda larga - conformista, em remissões aos conceitos de "cultura no plural" e "cultura no singular", estes evocados posteriormente por Michel Certeau (1995).

Talvez possamos finalizar propondo que uma telenovela como Rebelde mesmo que reiterando as ondas largas morinianas ou as formas instrumentais de Prokop pode, em sua incorporação cotidiana, atuar disruptivamente, na direção das trilhas tecidas pelos processos de ressignificação e de ironia. Lembrome aqui de uma situação presenciada na cidade de Natal, nas cercanias populares da rodoviária, que nos serve a esta proposição. Tratou-se de uma encenação assumidamente irônica e caricatural do RBD, capitaneada por um grupo de homens travestidos e grotescamente maquiados que circulavam em um carnaval improvisado, cantando e representando situações da telenovela, com elementos locais e até mesmo incorporação de situações que aconteciam no decorrer da apresentação $\square$ FAMEcos

\section{NOTAS}

* Algumas das reflexões contidas neste artigo serviram de base para palestra proferida (com colaboração de Renato Avanzi) em mesa da MULTICOM 2007, coordenada pela Profa. Dra. Maria Aparecida Baccega, decana do Programa de Mestrado da ESPM, SP.

1 Para uma análise dos meandros comunicacionais deste fenômeno, ver a dissertação BUDAG, Fernanda Elouise. Comunicação, recepção e consumo: suas inter-relações em Rebelde. São Paulo: ESPM, 2008.

\section{REFERÊNCIAS}

APPADURAI, Arjun. Disjunção e diferença na economia cultural global. In. FEATHERSTONE, Mike. Cultura global. Petrópolis: Vozes, 1999.

BAUMAN, Zygmunt. Amor líquido. Rio de Janeiro: Zahar, 2004.

CERTEAU, Michel. A cultura no plural. Campinas: Papirus, 1995.

DELEUZE, Gelles. \& GUATTARI, Félix. Micropolítica e segmentaridade. In: Mil Platôs. Capitalismo e esquizofrenia, Vol. 3. Rio de Janeiro: Ed 34, 1996.
DELEUZE, Gilles. Post-criptum sobre as sociedades de controle. In: Conversações. Rio de Janeiro: Ed 34, 1992.

ECO, Umberto. Apocalípticos e integrados. São Paulo: Perspectiva, 1979.

KOKOREFF, Michel. L'autocélébration de la televisión et ses paradoxes. In: Quaderni. Paris: CREDAP, Université Paris Dauphine, ${ }^{\circ} 9$, p.19-39, 1989/1990.

LANDOWSKY, Eric. Gosto se discute. In: LANDOWSKY, Eric e FIORIN, José Luiz (Org.). O gosto da gente, o gosto das coisas. São Paulo: EDUC, 1997.

LIPOVETSKY, Gilles. A era do vazio. Ensaio sobre o individualismo contemporâneo. Lisboa: Relógio D’Água, 1989.

MAUTNER, Anna Verônica. As grifes humanas. In: Folha de S. Paulo. São Paulo, 05 de dezembro de 2002.

MORIN, Edgar. Cultura de massas no século XX. Necrose. Rio de Janeiro: Forense Universitária, 2003.

PERNIOLA, Mario. Do sentir. Lisboa: Presença, 1993.

PROKOP, Dieter. Fascinação e tédio na comunicação. Produtos de monopólio e consciência. In: PROKOP, Dieter. Coleção Grandes Cientistas Sociais. São Paulo: Ática, 1986.

ROCHA, Rose de Melo. Você sabe para quem está olhando? In: BAITELLO, Norval (Org.). Os meios da (in)comunicação. São Paulo: Annablume, 2004. 